\title{
Group B streptococcal infections during pregnancy and perinatal consequences: what do we need to determine more than a bacteriological analysis?
}

\author{
Anca A. Simionescu ${ }^{1,2}$, Ana Maria Alexandra Stanescu ${ }^{1}$ \\ ${ }^{1 " C}$ Carol Davila" University of Medicine and Pharmacy, Bucharest, Romania \\ ${ }^{2}$ Filantropia Clinical Hospital, Bucharest, Romania
}

\begin{abstract}
Group B of streptococcal infection is responsible for maternal and fetal morbidity and mortality. Fetal consequences of streptococcal B infection may lead to puerperal sepsis, meningitis, encephalitis or pneumonia. Long-term consequences may determine neurological sequelae and mental disabilities, and very rare are reported cases for the late death of the child. Maternal consequences of streptococcal B infection are endometritis and sepsis. Universal screening and antibioprophylaxy during labour are safe and effective. But, systematic intrapartum prophylaxis for carriers of SGB does not appear to have effects on long-term complications. Also, systematic cultures in neonates do not appear to detect antenatally all carriers of streptococcus B. Herein, we present the particularity of streptococcal infection in pregnancy that may contribute to further strategy. Better laboratory tests for identifying serotypes, genotypes and phenotypes must be available, significantly to differentiate between dtreptococcal high- and low-risk regarding materno-fetal consequences.Immunization remains a promising way to eradicate this infection.
\end{abstract}

Keywords: pregnancy, Streptococcus agalactiae, hemolysin, immunology, membranes vesicle

\section{INTRODUCTION}

The vaginal mycobiome in pregnancy contributes to optimal fetoplacental functioning and is characterized by the predominance of Lactobacillus, Clostridiales, Bacteroidales, and Actinomycetales species (1). Group B Streptococcus (Streptococcus agalactiae, S.agalactiae, GBS) is a $\beta$-hemolytic Streptococcus, a Gram-positive bacterium, that is also part of the commensal vaginal flora but produces imbalances in the vaginal microbiota $(1,2)$. GBS is present in about 10 $40 \%$ of the female population $(3,4)$. The incidence of streptococcal B infection in newborns is estimated at 0.53 per 1,000 live births (5). Neonatal group B streptococcal infection is responsible for severe manifestations that have been noted since the early $1960 \mathrm{~s}(6,7)$.
These can cause early infection (first six days) when the infection has occurred by ascendent vaginally or may occur late (first three weeks) in the newborn. Group B streptococcal infection is responsible for: puerperal sepsis, meningitis, encephalitis or pneumonia. Long-term consequences may be responsible for the neurological sequelae and mental disabilities, and very rare are reported cases with for the late death of the child. Also, vaginal colonization with GBS increases the risk of 1.21 times for premature birth and intrauterine fetal death. Maternal vaginal colonization with GBS is responsible for 1-4\% of antepartum fetal deaths (8).

Almost $90 \%$ of cases of neonatal streptococcal B infection occur within the first 24 hours, and the risk of death is 2 times higher for early infection than for late infection $(5,9)$. 
Streptococcus B colonizes the digestive tract, from where it can enter the rectum, cervix and vagina. The infection can be transmitted by fecal-orally way, sexually or can cause infection of the amniotic fluid, placenta, amnio-chorial and fetal membranes.

Colonization of the female genital tract (cervix and vagina) has been reported for $18 \%$ of pregnancies worldwide (3).

The SGB culture from vaginal and/or anal area test are offered towards the end of pregnancy, between 34 and 36 completed weeks of pregnancy.

A level III maternity hospital study in Bucharest has reported $5.3 \%$ of pregnant women with streptococcal B infection (10).

Vaginal infection is often asymptomatic or can cause urinary tract infection detected by urine culture tests. Bacterial colonization is recurrent and may be present in subsequent pregnancies (11).

Based on a statistical analysis of data on the severity of streptococcal infection in newborns, the World Health Organization recommends universal screening for pregnant women through cultures of vaginal secretion and intrapartum prophylaxis of those with vaginal colonization, or for those with risk factors for fetal contamination (e.g. prolonged membranes rupture after 18 hours of labour), as well as antibiotic treatment of urinary SGB infections in pregnancy (12). Prophylactic treatment is empirical, with intravenous administration of Ampicillin and Gentamicin. The Romanian Society of Obstetrics and Gynecology guidelines recommends antibiotic prophylaxis based on risk factors or in the case of labour that has ruptured membranes over 12 hours (13), and in Romania, there are still doctors who recommended multiple antibiotics schemas during pregnancy.

No recognized authority recommends the treatment of vaginal colonization with Streptococcus B during pregnancy, outside of labour. Antibiotics cannot sterilize the vagina and may cause antibiotic resistance and disturbances of the fetal microbiome with long-term consequences on child immunity (1416).

The widespread use of antibiotic therapy in pregnancy has led to increased antibiotic resistance. A Romanian study shows an increase in cases of erythromycin resistance in the population of pregnant women with streptococcus B (17).

Instead, intrapartum prophylaxis with antibiotics is widely used. A meta-analysis of 8718 cases of in- fants SGB infection demonstrates that systematic intrapartum prophylaxis for carriers of SGB does not appear to have effects on long-term complications. Also, systematic cultures in neonates do not appear to detect antenatally all carriers of streptococcus B (5).

Nevertheless, then, rightly, we wonder what other strategies should be adopted to reduce fetal contamination?

\section{STREPTOCOCCAL B STRUCTURE AND IMMUNOLOGIC MECHANISM FOR MATERNAL-FETAL COLONIZATION}

There are ten serotypes of GBS based on polysaccharide capsule of 10 antigenic types (Ia, Ib, II, III, IV, V, VI, VII, VIII, IX), which correspond with specific serotypes. Worldwide distribution of group B streptococcus serotypes follow the same patterns and are similar between geographical areas. In a systematic review, serotype III is founded in more than $50 \%$ of all the infants isolates (including cultures, PCR or serologies), followed by serotype Ia, II, and V. The majority of late-onset disease and a high proportion of early-onset disease with a high mortality rate in neonates have been associated with serotype III worldwide (18-20).

The polysaccharide capsule is the most important virulence factor of $S$. agalactiae, and are implicated in the mechanism of evading host defence (21).

The virulence of SGB can be explained by the aggressiveness of the bacterium and by the host response following infection. Animal models in rabbit, monkey, and mouse investigated the role of cytokines and the immune response after the vaginal bacterial ascension and after various treatments (22).

Maternal and fetal pathological consequences depend on the response of the host represented by local reactions in the vaginal, placental, amniotic fluid and virulence of the pathogen.

The virulence of Streptococcus B can be explained by the particular structure that presents those surface proteins, pili and cilia, with a role in the mechanism of adhesion, invasion, which prevents the host response. GBS is demonstrating to adhere to and invade both chorionic and amniotic epithelial cells. GBS induces the secretion of multiple cytokines and defensins from placental membranes (TNF- $\alpha$, IL- $1 \alpha$, IL-1 $\beta$, IL-6, and IL-8) (20).

GBS uses hyaluronidases (HylB ) to promote both vaginal colonization and invasive disease. $\mathrm{HylB}$, is 
an endoglycosidase that cleaves glycosaminoglycan chains, such as hyaluronic acid (HA) into disaccharides (23). An important role in GDS aggressiveness is played by hemolytic pigment (being hemolytic $\beta$-Streptococcus B) and hyaluronidase. GBS may produce extracellular membrane vesicles responsible for the survival, virulence and dissemination of the pathogens in the host . Extracellular membrane vesicles are supposed to disrupt feto-maternal barrier and weaned placental membranes (24).

At the vaginal level, GDS aggression causes an immune response mediated by neutrophils, mast cells and macrophages. Inflammatory cytokines and chemokines IL-1 $\beta$, IL-6, IL-8, IL-17, IL-23, and histamine play an essential role in reducing GBS vaginal colonization and include. Recent studies have shown that IL-17 and IL-17+ cells play an important role in the clearance of a hyper-adherent and invasive GBS strain from the vagina (25), suggesting that the $\mathrm{T}_{\mathrm{H}} 17$ cells implicate in inflammatory response and $\mathrm{T}_{\mathrm{H}} 17$ differentiation pathway are important for controlling persistent GBS colonization.

Studies on Macaca nemestrina demonstrate that choriodecidual GBS inoculation induces fetal lung injury without intra-amniotic infection and preterm labour (26). Fetal injury is not entirely dependent on the bacterial invasion of fetal tissues. Fetal lung injury can also be caused by GBS-induced chorioamnionitis without bacterial invasion. But, increases in immunological response manifested by the release of amniotic fluid cytokines contribute to fetal lung injury, and dysregulation of fetal lung development $(25,27,28)$.

GBS contamination of the fetus in utero leads to a multitude of adverse outcomes. This may affect multiple organs the lung, blood, liver, spleen and gastrovascular cavity. GBS contamination produces tissue damage, inflammation, lung and brain injury. This manifest as pneumonia, meningitis, sepsis, and even can lead to fetal death. A significant observation is that fetal tissue damage is not linked with bacterial invasion; tissue damage has been observed in the presence and absence of bacterial invasion, but only consecutive to inflammation produced in the gestational tissues and amniotic fluid (24).

Early infection is thought to occur more due to infection of amniotic fluid and chorioamnionitis. Factors that would stop the ascending transmission may be: cervical barrier, local immunity, and the amount of hyaluronic acid at this level that may protect against infection (29).
Carey et al. demonstrate the role of hemolysin in persistence and neutrophil accumulation. GBS strain lacking the hemolytic pigment is a deficient vaginal colonizer compared to wild-type GBS, due to the mobilization of neutrophils and rise in cellular defence (30). However, GBS over-expressing the hemolytic pigment was more readily cleared from the murine vagina (31), likely due to an inflammatory response with neutrophils accumulation and/or mast cell degranulation (28). GBS must achieve an optimum level of hemolytic pigment production to survive and avoid inflammation and subsequent clearance.

In addition to modulating vaginal colonization, the hemolytic pigment permits GBS dissemination to host niches outside the vagina and facilitates tissue damage. It has been demonstrated that the hemolytic pigment plays a role in GBS's ability to traverse placenta. Hyper-hemolytic GBS strains lacking were found to more readily invade amniotic epithelial cells, cause amniotic epithelial cell barrier disruption, and penetrate placenta (32).

In a murine model of vaginal colonization, nonhemolytic GBS was less likely to disseminate or cause fetal injury suggesting the hemolytic pigment plays a role in GBS's ability to pass the placenta into the amniotic fluid (33). Also, for infants, higher expression of the hemolytic pigment founded in lung tissues are correlates to higher toxicity (34).

\section{QUESTIONS TO BE ANSWERED}

Although 20 years ago, the complete genome sequence of Streptococcus agalactiae became available, the biological role of surface proteins (potential virulence factors or targets for protective immunity) was analyzed, we don't find biological markers that correlate with the severity of disease $(35,36)$. Surprisingly, multi-locus sequence typing (MLST) of GBS showed that most human carriage and clinical isolates cluster is represented by five major clonal complexes (CC) (CC1, CC10, CC17, CC19 and CC23) (37).

Immunization remains a promising way to eradicate this infection. More than 20 years ago, GBS vaccine candidates and several multivalent capsular multivalent conjugate vaccines had shown promising safety and immunogenicity outcomes in phase I and II clinical trials. However, the diversity of GBS types remains significant challenges to the development of broadly efficacious GBS vaccines (38-44). 
GBS $\beta$-hemolytic remains a global public health issue consecutive to neonatal mortality and morbidity. New strategies to screen high-risk population and to prevent vertical transmission need to be developed. Serological detection only of the presence or absence of GBS is insufficient, serotype, genotype and phenotype must be established, especially of the forms that increase the invasiveness and virulence associated with pulmonary and cerebral tropism. One of the remaining questions to be answered is about

\section{REFERENCES}

1. Brzychczy-Włoch M, Pabian W, Majewska E, Zuk MG, Kielbik J, Gosiewski T, Bulanda MG. Dynamics of colonization with group B streptococci in relation to normal flora in women during subsequent trimesters of pregnancy. New Microbiol. 2014 Jul;37(3):307-19.

2. Kubota $T$, Nojima M, Itoh $S$. Vaginal bacterial flora of pregnant women colonized with group B streptococcus. J Infect Chemother. 2002 Dec;8(4):326-30.

3. Russell NJ, Seale AC, O'Driscoll M, O'Sullivan C, Bianchi-Jassir F, Gonzalez-Guarin J, Lawn JE, et al.; GBS Maternal Colonization Investigator Group. Maternal Colonization With Group B Streptococcus and Serotype Distribution Worldwide: Systematic Review and Meta-analyses. Clin Infect Dis. 2017 Nov 6;65(suppl_2):S100-S111.

4. Kwatra G, Cunnington MC, Merrall E, Adrian PV, Ip M, Klugman KP, Tam WH, Madhi SA. Prevalence of maternal colonisation with group B streptococcus: a systematic review and meta-analysis. Lancet Infect Dis. 2016 Sep;16(9):1076-1084.

5. Edmond KM, Kortsalioudaki C, Scott S, Schrag SJ, Zaidi AK, Cousens S, Heath PT. Group B streptococcal disease in infants aged younger than 3 months: systematic review and meta-analysis. Lancet. 2012 Feb 11;379(9815):547-56.

6. Eickhoff TC, Klein JO, Daly AK, Ingall D, Finland M. Neonatal sepsis and other infections due to group $b$ beta-hemolytic streptococci. N Engl J Med. 1964 Dec 10;271:1221-8.

7. Kexel G, Schoenbohm S. Streptococcus agalactiae as the causative agent in infantile meningitis. Dtsch Med Wochenschr. $1965 \mathrm{Feb}$ 5:90:258-61.

8. Seale AC, Blencowe H, Bianchi-Jassir F, Embleton N, Bassat Q, Ordi J, Menéndez C, et al. Stillbirth With Group B Streptococcus Disease Worldwide: Systematic Review and Meta-analyses. Clin Infect Dis. 2017 Nov 6;65(suppl_2):S125-S132.

9. Bianchi-Jassir F, Seale AC, Kohli-Lynch M, Lawn JE, Baker CJ, Bartlett L, et al. Preterm Birth Associated With Group B Streptococcus Maternal Colonization Worldwide: Systematic Review and Meta-analyses. Clin Infect Dis. 2017 Nov 6; 65(suppl_2):S133-S142.

10. Broscăuncianu D, Bănceanu G, Stoicescu SM. Streptococ Grup B - factor de risc pentru infecţie perinatală. Obstetrica si Ginecologia 2014;62:105-112.

11. Manning SD, Neighbors K, Tallman PA, Gillespie B, Marrs CF, Borchardt SM, Baker CJ, Pearlman MD, Foxman B. Prevalence of group B streptococcus colonization and potential for transmission by casual contact in healthy young men and women. Clin Infect Dis. 2004 Aug 1;39(3):380-8.

12. WHO recommendations for prevention and treatment of maternal peripartum infections. Available at: https://www.who.int/ reproductivehealth/publications/maternal_perinatal_health/ peripartum-infections-brief/en/ (accessed on May 2021).

13. Profilaxia cu antibiotic in obstetrica si ginecologie. Available at: SOGR http://sogr.ro>profilaxia-antibiotica-in-obstetrica 2019/05. the real value of actual screening in the third trimester of pregnancy and tests specificity.

\section{CONCLUSIONS}

There are multiple faces of GBS infection, and it's relation with maternal and fetal complication. Screening test by vaginal and rectal culture may be used, and complementary laboratory findings may help discriminate low- versus high GBS infection risks.

Conflict of interest: none declared Financial support: none declared

14. Bedford Russell AR, Murch SH. Could peripartum antibiotics have delayed health consequences for the infant? BJOG. 2006 Jul;113(7):758-65.

15. Langdon A, Crook N, Dantas G. The effects of antibiotics on the microbiome throughout development and alternative approaches for therapeutic modulation. Genome Med. 2016 Apr 13;8(1):39.

16. Tormo-Badia N, Håkansson A, Vasudevan K, Molin G, Ahrné S, Cilio $\mathrm{CM}$. Antibiotic treatment of pregnant non-obese diabetic mice leads to altered gut microbiota and intestinal immunological changes in the offspring. Scand J Immunol. 2014 Oct;80(4):250-60.

17. Usein CR, Petrini A, Georgescu R, Grigore L, Străuţ M, Ungureanu V. Group B streptococcus colonization of Romanian women: phenotypic traits of isolates from vaginal swabs. Roum Arch Microbiol Immunol. 2009 Oct-Dec;68(4):235-9.

18. Madrid L, Seale AC, Kohli-Lynch M, Edmond KM, Lawn JE, Heath PT, et al.; Infant GBS Disease Investigator Group. Infant Group B Streptococcal Disease Incidence and Serotypes Worldwide: Systematic Review and Meta-analyses. Clin Infect Dis. 2017 Nov 6;65(suppl_2):S160-S172.

19. Nanduri SA, Petit S, Smelser C, Apostol M, Alden NB, Harrison LH, et al.. Epidemiology of Invasive Early-Onset and Late-Onset Group B Streptococcal Disease in the United States, 2006 to 2015: Multistate Laboratory and Population-Based Surveillance. JAMA Pediatr. 2019 Mar 1;173(3):224-233.

20. Armistead B, Oler E, Adams Waldorf K, Rajagopal L. The Double Life of Group B Streptococcus: Asymptomatic Colonizer and Potent Pathogen. J Mol Biol. 2019 Jul 26;431(16):2914-2931.

21. Le Doare K, Heath PT. An overview of global GBS epidemiology. Vaccine. 2013 Aug 28;31 Suppl 4:D7-12.

22. McDuffie RS, Gibbs RS. Animal models of ascending genital-tract infection in pregnancy. Infect Dis Obstet Gynecol. 1994;2(2):60-70.

23. Pritchard DG, Lin B, Willingham TR, Baker JR. Characterization of the group B streptococcal hyaluronate lyase. Arch Biochem Biophys. 1994 Dec;315(2):431-7.

24. Surve MV, Anil A, Kamath KG, Bhutda S, Sthanam LK, Pradhan A, Srivastava R, Basu B, Dutta S, Sen S, Modi D, Banerjee A. Membrane Vesicles of Group B Streptococcus Disrupt FetoMaternal Barrier Leading to Preterm Birth. PLoS Pathog. 2016 Sep 1;12(9):e1005816.

25. Patras KA, Rösler B, Thoman ML, Doran KS. Characterization of host immunity during persistent vaginal colonization by Group B Streptococcus. Mucosal Immunol. 2015 Nov;8(6):1339-48.

26. Adams Waldorf KM, Gravett MG, McAdams RM, Paolella LJ, Gough GM, Carl DJ, Bansal A, Liggitt HD, Kapur RP, Reitz FB, Rubens CE. Choriodecidual group $B$ streptococcal inoculation induces fetal lung injury without intra-amniotic infection and preterm labor in Macaca nemestrina. PLoS One. 2011;6(12):e28972.

27. Carey AJ, Tan CK, Mirza S, Irving-Rodgers H, Webb RI, Lam A, Ulett GC. Infection and cellular defense dynamics in a novel $17 \beta$-estradiol murine model of chronic human group B streptococcus 
genital tract colonization reveal a role for hemolysin in persistence and neutrophil accumulation. J Immunol. 2014 Feb 15; 192(4):1718-31.

28. Gendrin C, Vornhagen J, Ngo L, Whidbey C, Boldenow E, Santana-Ufret V, Clauson M, Burnside K, Galloway DP, Adams Waldorf KM, Piliponsky AM, Rajagopal L. Mast cell degranulation by a hemolytic lipid toxin decreases GBS colonization and infection. Sci Adv. 2015 Jul 17;1(6):e1400225.

29. Akgul Y, Word RA, Ensign LM, Yamaguchi Y, Lydon J, Hanes J, Mahendroo M. Hyaluronan in cervical epithelia protects against infection-mediated preterm birth. J Clin Invest. 2014 Dec; 124(12):5481-9.

30. Carey AJ, Tan CK, Mirza S, Irving-Rodgers H, Webb RI, Lam A, Ulett GC Infection and cellular defense dynamics in a novel $17 \beta$-estradiol murine model of chronic human group B streptococcus genital tract colonization reveal a role for hemolysin in persistence and neutrophil accumulation. J Immunol. 2014 Feb 15; 192(4):1718-31.

31. Patras KA, Wang NY, Fletcher EM, Cavaco CK, Jimenez A, Garg M, Fierer J, Sheen TR, Rajagopal L, Doran KS. Group B Streptococcus CovR regulation modulates host immune signalling pathways to promote vaginal colonization. Cell Microbiol. 2013 Jul;15(7):1154-67.

32. Whidbey C, Harrell Ml, Burnside K, Ngo L, Becraft AK, lyer LM, Aravind L, Hitti J, Adams Waldorf KM, Rajagopal L. A hemolytic pigment of Group B Streptococcus allows bacterial penetration of human placenta. J Exp Med. 2013 Jun 3;210(6):1265-81.

33. Vornhagen J, Adams Waldorf KM, Rajagopal L. Perinatal Group B Streptococcal Infections: Virulence Factors, Immunity, and Prevention Strategies. Trends Microbiol. 2017;25(11):919-931.

34. Gibson RL, Nizet V, Rubens CE. Group B streptococcal betahemolysin promotes injury of lung microvascular endothelial cells. Pediatr Res. 1999 May;45(5 Pt 1):626-34.

35. Tettelin H, Masignani V, Cieslewicz MJ, Eisen JA, Peterson S, Wessels MR, et al. Complete genome sequence and comparative genomic analysis of an emerging human pathogen, serotype $\mathrm{V}$ Streptococcus agalactiae. Proc Natl Acad Sci USA. 2002 Sep 17; 99(19):12391-6.
36. Faralla C, Metruccio MM, De Chiara M, Mu R, Patras KA, Muzzi A, Grandi G, Margarit I, Doran KS, Janulczyk R. Analysis of twocomponent systems in group B Streptococcus shows that RgfAC and the novel FspSR modulate virulence and bacterial fitness. mBio. 2014 May 20;5(3):e00870-14.

37. Jones N, Bohnsack JF, Takahashi S, Oliver KA, Chan MS, Kunst F, Glaser P, Rusniok C, Crook DW, Harding RM, Bisharat N, Spratt BG. Multilocus sequence typing system for group $B$ streptococcus. J Clin Microbiol. 2003 Jun;41(6):2530-6.

38. Kobayashi M, Schrag SJ, Alderson MR, Madhi SA, Baker CJ, Sobanjo-Ter Meulen A, Kaslow DC, Smith PG, Moorthy VS, Vekemans J. WHO consultation on group B Streptococcus vaccine development: Report from a meeting held on 27-28 April 2016. Vaccine. 2019 Nov 28;37(50):7307-7314.

39. Baker CJ, Rench MA, Fernandez M, Paoletti LC, Kasper DL, Edwards MS. Safety and immunogenicity of a bivalent group B streptococcal conjugate vaccine for serotypes II and III. J Infect Dis. 2003 Jul 1;188(1):66-73.

40. Baker CJ, Paoletti LC, Wessels MR, Guttormsen HK, Rench MA, Hickman ME, Kasper DL. Safety and immunogenicity of capsular polysaccharide-tetanus toxoid conjugate vaccines for group B streptococcal types la and Ib. J Infect Dis. 1999 Jan;179(1):142-50.

41. GlaxoSmithKline. Safety and Immunogenicity of a Trivalent Group B Streptococcus Vaccine in Healthy Pregnant Women (NCT02046148). 2017.

42. Novartis. Safety and Immunogenicity of a Group B Streptococcus Vaccine in Non Pregnant and Pregnant Women 18-40 Years of Age (NCT01193920). ClinicalTrials.gov2014.

43. Novartis. Immune Response Induced by a Vaccine Against Group B Streptococcus and Safety in Pregnant Women and Their Offsprings (NCT01446289). ClinicalTrials.gov2014.

44. Bellais S, Six A, Fouet A, Longo M, Dmytruk N, Glaser P, Trieu-Cuot $\mathrm{P}$, Poyart C. Capsular switching in group B Streptococcus CC17 hypervirulent clone: a future challenge for polysaccharide vaccine development. J Infect Dis. 2012 Dec 1;206(11):1745-52. 